\title{
Retinoblastoma Expression in Thyroid Neoplasms
}

Faten Anwar, M.D., Mary J. Emond, Ph.D., Rodney A. Schmidt, M.D., Ph.D., Harry C. Hwang, M.D., Mary P. Bronner, M.D.

Departments of Pathology (FA, RAS, HCH, MPB) and Biostatistics (MJE), University of Washington, Seattle, Washington

Retinoblastoma $(\mathbf{R b})$ mutation in thyroid neoplasia has been identified in a few molecular studies; however, the utility of Rb immunohistochemistry in distinguishing benign and malignant thyroid lesions has not been documented in formalin-fixed, paraffin-embedded tissues. The present study investigated $R \mathbf{R}$ immunohistochemistry in a series of 111 formalin-fixed, paraffin-embedded benign and malignant thyroid lesions. All of the major histologic subtypes were included to detect any heterogeneity in Rb-1 expression that might influence the diagnostic utility of this technique or further elucidate the pathogenesis of thyroid neoplasia among the categories. Altogether, 34 follicular adenomas, 9 follicular carcinomas, 7 Hürthle cell adenomas, 5 Hürthle cell carcinomas, 23 papillary carcinomas ( 8 of which were follicular variants), 4 insular carcinomas, 4 anaplastic carcinomas, 6 medullary carcinomas, and 19 nodular goiters were analyzed. Avidinbiotin immunohistochemistry was performed using the Dako Rb-1 clone. Pronase digestion was introduced into the epitope retrieval protocol to eliminate false-positive cytoplasmic staining. Nuclear immunoreactivity was assessed as positive if $10 \%$ or more of thyroid epithelial nuclei stained positively, and conversely as negative. The majority of benign non-Hürthle thyroid lesions, whether hyperplastic or neoplastic, retained $\mathrm{Rb}$ nuclear immunopositivity in most cells (51 of 53 cases [96\%]). Conversely, malignant thyroid neoplasms lacked Rb immunoreactivity in the majority (42 of 51 cases $[82 \%]$ ), including all papillary carcinomas (23 of 23 ) and almost all follicular carcinomas (8 of 9 [89\%]). Virtually all Hürthle cell neoplasms were negative (11 of 12 [92\%]), whether benign or malignant. In conclusion, $\mathbf{R b}$ immunohistochemistry can aid in the distinction between benign and malignant thyroid

Copyright (C) 2000 by The United States and Canadian Academy of Pathology, Inc.

VOL. 13, NO. 5, P. 562, 2000 Printed in the U.S.A.

Date of acceptance: October 26, 1999.

Address reprint requests to: Mary P. Bronner, M.D., University of Washington, Department of Pathology, 1959 N.E. Pacific Street, Box 356100, Seattle, WA 98195-6100; e-mail: bronner@u.washington.edu; fax: 206-5484928. lesions in conjunction with morphology. This seems to be most applicable to the often problematic differentiation between follicular adenoma and the follicular variant of papillary carcinoma $(P<\mathbf{. 0 0 0 1}$; sensitivity and specificity, $100 \%)$ or minimally invasive follicular carcinoma ( $P=.0007$; sensitivity, 89\%; specificity, 100\%).

KEY WORDS: Immunohistochemistry, Nodular goiter, Paraffin-embedded tissue, Retinoblastoma, Thyroid neoplasm.

Mod Pathol 2000;13(5):562-569

Retinoblastoma $(\mathrm{Rb})$ was the first discovered tumor-suppressor gene (1-3). It maps to chromosome 13q14 and encodes a 110-114 KD nuclear protein that plays a major role in the regulation of cell growth arrest $(4-6)$. Rb protein product $(\mathrm{P}-\mathrm{Rb})$ is expressed in all cells, where it exists in an active hypophosphorylated and an inactive hyperphosphorylated state. In its active state, P-Rb serves as a brake on the advancement of cells from G1 to $S$ phase of the cell cycle. When the cells are stimulated by growth factors, $\mathrm{Rb}$ protein is inactivated by phosphorylation, allowing the cells to transverse the G1-S checkpoint. Once cells enter the S phase, they are committed to divide. During the ensuing $M$ phase, phosphate groups are removed from $\mathrm{P}-\mathrm{Rb}$ by cellular phosphatases, thus regenerating the active hypophosphorylated form of the protein (5-8). The hypophosphorylated $\mathrm{P}-\mathrm{Rb}$ achieves cell cycle arrest by forming a complex with the E2F family of transcription factors. These complexes bind to DNA and actively inhibit the transcription of S-phase genes, thereby preventing cell division (5-9).

Germline loss or mutation of the Rb gene predisposes to the development of retinoblastoma and to a lesser extent osteosarcoma. Its role in the pathogenesis of retinoblastoma has been elegantly explained by Knudson's two-hit hypothesis (2). Furthermore, somatically acquired $\mathrm{Rb}$ mutations have been described in glioblastomas; sarcomas; small cell and non-small cell carcinomas of the lung; and breast, prostatic, and bladder carcinomas (10-20). 
A number of studies have investigated the role of proto-oncogene activation in thyroid neoplasia. Activation of c-erb, c-fos, c- myc, and ras, among other genes, has been described (21-25). However, the diagnostic utility of these findings is limited by the occurrence of these abnormalities in both benign and malignant tumors (21-25). The role of tumorsuppressor gene loss in carcinogenesis has been documented in multiple tumors. p53 is the most notable example and has also been described in thyroid tumorigenesis (26-28).

The presence of $\mathrm{Rb}$ mutation in thyroid neoplasms has been documented in a small number of cases (29-31). Rb protein immunohistochemistry in malignant thyroid tumors has generated controversial results in the few published studies (29-31). The only study that has evaluated the diagnostic utility of Rb immunohistochemistry in the differential diagnosis of benign and malignant thyroid lesions analyzed only nine thyroid tumors by molecular and immunohistochemical assays limited to frozen sections and cytospin preparations (29). The usefulness of $\mathrm{Rb}-1$ antibody in paraffin sections in distinguishing benign and malignant thyroid neoplasms has not been evaluated.

The objective of the current study was to evaluate $\mathrm{Rb}-1$ immunohistochemistry in routine formalinfixed, paraffin-embedded benign and malignant thyroid disorders. We introduce a modified technique that does not have the drawback of high cytoplasmic background as documented in the few studies evaluating $\mathrm{Rb}$ protein expression in paraffin sections (32-34). We stratified thyroid lesions into the major histologic subtypes to detect any heterogeneity in Rb-1 expression that might influence the diagnostic utility of this technique or further elucidate the pathogenesis of thyroid neoplasia.

\section{MATERIALS AND METHODS}

\section{Case Selection}

Representative sections of $10 \%$ neutral-buffered, formalin-fixed, paraffin-embedded tissue were obtained from 111 different patients' thyroid lesions, representing all of the major subtypes of thyroid neoplasms (Table 1). The cases included specimens from the archived files at the University of Washington Department of Pathology, as well as cases from the senior author's consultation service (MPB). All hematoxylin and eosin-stained slides on each case were reviewed to confirm the diagnoses using standard histologic criteria $(35,36)$ and to ensure that representative sections were submitted for immunohistochemical analysis. The diagnosis of medullary carcinoma versus follicular carcinoma was confirmed in each case by standard anticalcitonin and antithyroglobulin immunopositivity, respectively.

\section{Immunohistochemistry}

Analyses were performed using an avidin-biotin immunoperoxidase method. Four-micron-thick tissue sections were cut and placed on electrostatically charged slides and heated to $60^{\circ} \mathrm{C}$ for $15 \mathrm{~min}$. The tissues were then deparaffinized, rehydrated, and incubated in 3\% hydrogen peroxide for $5 \mathrm{~min}$ to block endogenous peroxidase and then washed in $\mathrm{dH}_{2} \mathrm{O}$. Heat-induced epitope retrieval was performed by microwaving for $18 \mathrm{~min}$ in $10 \mathrm{~mm}$ citrate buffer at pH 6.0. Sections were held in hot buffer for $20 \mathrm{~min}$, washed in phosphate buffered saline (PBS) buffer, and then incubated for $10 \mathrm{~min}$ with pronase ( $0.1 \mathrm{gram} / \mathrm{L}$ at room temperature; Calbiochem, La Jolla, CA). The 10-min incubation time is the optimal time for digestion with this enzyme as determined from our laboratories' experience in our referral service and hospital practice. We selected this concentration and time after titration at different incubation times and with different concentrations of pronase. Using this combination of timing and concentration, we determined this to be optimal for preservation of tissue integrity and immunoreactivity. The sections were then washed in PBS, at which point the monoclonal primary antibody Rb-1 (Dako, Carpinteria, CA) was applied for $45 \mathrm{~min}$ at room temperature at a 1:50 dilution. Sections were then washed in PBS, and a biotinylated antimouse secondary antibody (Vector Laboratories, Burlingame, CA; 1:200) was applied for $25 \mathrm{~min}$. Again the

TABLE 1. Rb-1 Immunohistochemical Results in Thyroid Neoplasms

\begin{tabular}{lrcc}
\hline \multicolumn{1}{c}{ Diagnosis } & $N$ & Rb Negative $(<10 \%$ cells stained $)$ & Rb Positive $(\geq 10 \%$ cells stained $)$ \\
\hline Follicular adenoma & 34 & $0(0 \%)$ & $34(100 \%)$ \\
Nodular goiter & 19 & $2(11 \%)$ & $17(89 \%)$ \\
Follicular carcinoma & 9 & $8(89 \%)$ & $1(11 \%)$ \\
Papillary carcinoma follicular variant & 8 & $8(100 \%)$ & $0(0 \%)$ \\
Papillary carcinoma & 15 & $15(100 \%)$ & $0(0 \%)$ \\
Hürthle cell carcinoma & 5 & $4(80 \%)$ & $1(20 \%)$ \\
Hürthle adenoma & 7 & $7(100 \%)$ & $0(0 \%)$ \\
Insular carcinoma & 4 & $4(100 \%)$ & $0(0 \%)$ \\
Anaplastic carcinoma & 4 & $0(0 \%)$ & $4(100 \%)$ \\
Medullary carcinoma & 6 & $3(50 \%)$ & $3(50 \%)$ \\
\hline
\end{tabular}


sections were washed in PBS, and the avidin-biotin complex (Vector Laboratories; 1:100) was applied for an additional 25-min incubation. Diaminobenzidine tetrahydrochloride enhanced with $8 \% \mathrm{NiCl}_{2}$ was used for the chromogen black reaction product, followed by methyl green counterstaining, dehydration, and coverslipping.

Positivity was observed in the nuclei as black staining. The endothelial cells and lymphocytes served as positive internal controls as an additional step to monitor the retrieval and immunohistochemical techniques. The total number of positive epithelial cells in each tumor was estimated as a percentage of the total number of epithelial cells in the lesion, in $10 \%$ incremental semiquantitative assessments, by two observers independently. Reactivity in $10 \%$ or more of thyroid epithelial cell nuclei was considered positive, and less than $10 \%$ was considered negative, based on previous work using quantitative image analysis (29).

\section{Statistical Analysis}

Differences in percentage of tumors that were positive for immunoreactivity among the 10 subtypes of lesions were tested for significance using the likelihood ratio $\chi^{2}$ statistic with a small constant $\left(10^{-8}\right)$ added to every category to make numerical adjustment for sampling zeros (37). Because hundreds of comparisons are possible among the 10 subtypes, adjustment for multiple comparisons was done using the procedure of Gabriel (38). This procedure preserves the overall type 1 error rate (i.e., false-positive rate or "alpha-level") at 0.05 so that the probability of making no type 1 errors in any of the comparisons remains at $95 \%$.

\section{RESULTS}

The staining pattern with $\mathrm{Rb}-1$ was a diffuse nuclear reactivity. We did not observe nonspecific cytoplasmic binding as reported previously (32-34). The cytoplasmic element of staining was eliminated by the addition of a 10-min incubation with pronase in the antigen retrieval procedure after microwaving. On comparing the quality of staining with and without pronase digestion, there was no change in the percentage of positive cells, but the cytoplasmic background staining was eliminated by pronase digestion. This rendered the ratio of noise to signal significantly lower and the task of evaluating the nuclear staining easier and more accurate.

Mesenchymal fibroblasts and endothelial cells and lymphoid cells within thyroid neoplasms and goiters consistently showed nuclear positivity but were not included in the percentages of positive cells in this study. Only thyroid epithelial cells were assessed using a $10 \%$ or greater cutoff for positivity.
In addition and in all cases, internal control nonneoplastic thyroid tissue reacted positively in a portion of epithelial cell nuclei. This, along with the mesenchymal cell and lymphoid cell staining, served as internal staining quality control for all cases. In addition and in parallel with all experiments, an external positive control thyroid follicular adenoma reacted consistently with the antibody in the majority of the cells.

The majority of benign thyroid lesions (Table 1) were positive for Rb nuclear immunoreactivity, including 34 of 34 follicular adenomas (100\%) and 17 of 19 nodular goiters (89\%) (Fig. 1). The great majority of positive lesions reacted in most of the lesional nuclei. In all but two follicular adenomas and one nodular goiter nodule, more than $50 \%$ of lesional nuclei stained positively. In the three discrepant lesions, only $20 \%$ of the lesional cells in the two cases and only $10 \%$ in the third case showed nuclear immunoreactivity. Using a $10 \%$ cutoff, we assessed these three cases as positive. In general, however, using a $10 \%$ cutoff, the great majority of positive benign lesions (51 of 53 [95\%]) were clearly and easily assessed as positive for Rb nuclear immunoreactivity because the majority $(>50 \%)$ of cells were positive.

As for malignant neoplasms (Table 1), all 23 cases of papillary carcinoma showed lack of expression of $\mathrm{P}-\mathrm{Rb}$, as defined by reactivity in fewer than $10 \%$ of the tumor cell nuclei (Fig. 1). Our study also included nine cases of follicular carcinoma, of which only one showed $\mathrm{Rb}$ expression and eight were negative. Medullary carcinomas reacted positively in 3 of $6(50 \%)$ cases, whereas the remaining three cases $(50 \%)$ lacked expression of P-Rb. The four cases of anaplastic carcinoma we analyzed all showed strong positive staining (Fig. 2), in contrast to an adjoining insular carcinoma component in one case and a papillary carcinoma component in another case, both of which were negative.

It is interesting that almost all of the Hürthle cell neoplasms lacked $\mathrm{Rb}-1$ expression, whether benign or malignant. Only one of five carcinomas was positive, and seven adenomas were negative (Fig. 3).

Together, these results have significant implications for improving the accuracy of difficult differential diagnoses in thyroid pathology. One hundred percent of follicular adenomas were positive $(95 \%$ confidence interval $[\mathrm{CI}]=[85 \%, 100 \%])$. This was in marked contrast to the $11 \%$ positive in follicular carcinomas $(95 \% \mathrm{CI}=[0.3 \%, 48 \%])$ and the $0 \%$ positive found in papillary carcinoma including the follicular variant $(95 \% \mathrm{CI}=[0 \%, 13 \%]$. When the percentage positive for immunoreactivity in follicular adenoma was compared with the percentage positive in each of the other subtypes, it was found that the percentage positive in follicular adenoma was significantly greater than in follicular carci- 

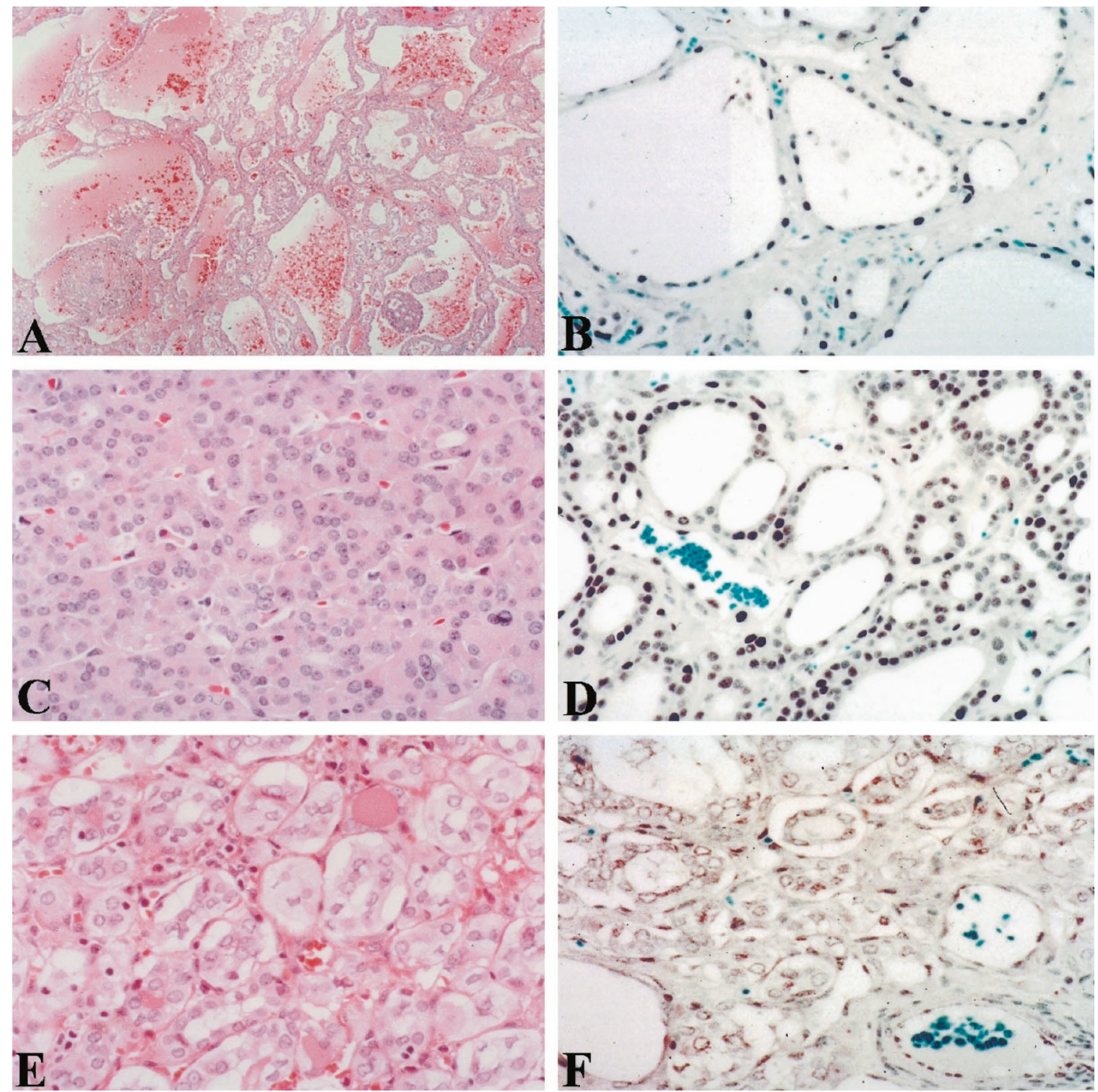

FIGURE 1. A, nodular goiter (hematoxylin and eosin). B, same nodular goiter showing retinoblastoma (Rb) immunoreactivity in almost all nuclei ( $\mathrm{Rb}$ immunohistochemistry with diaminobenzidine (DAB) chromogen and nickel chloride enhancement to produce a black positive signal against methyl green counterstaining). C, follicular adenoma (hematoxylin and eosin). D, same follicular adenoma showing Rb immunoreactivity in almost all nuclei $(\mathrm{Rb}$ immunohistochemistry with $\mathrm{DAB}$ chromogen and nickel chloride enhancement to produce a black positive signal against methyl green counterstaining). E, follicular variant of papillary carcinoma (hematoxylin and eosin). F, same follicular variant of papillary carcinoma showing complete absence of $\mathrm{Rb}$ immunoreactivity ( $\mathrm{Rb}$ immunohistochemistry with $\mathrm{DAB}$ chromogen and nickel chloride enhancement to produce a black positive signal against methyl green counterstaining).

noma, papillary carcinoma (follicular variant), papillary carcinoma, Hürthle adenoma, and insular carcinoma $\left(P=.0007, P<.0001, P<10^{-7}, P=\right.$ .0003 , and $P=.02$, respectively, after adjustment for multiple comparisons). When viewed as a diagnostic test for differentiating follicular adenoma from follicular carcinoma, the percentage negative in follicular carcinoma corresponds directly to the test sensitivity $(89 \%$ sensitivity with $95 \% \mathrm{CI}=[52 \%$, $99.7 \%]$ ), whereas the percentage positive in follicular adenoma $(97 \%)$ corresponds to the specificity $(95 \%$ CI $=[85 \%, 99.9 \%])$. Similarly, the estimated sensitivity for diagnosing papillary carcinoma (follicular variant) versus follicular adenoma is $100 \%$
$(95 \% \mathrm{CI}=[69 \%, 100 \%])$ with the same specificity as in the previous differential diagnosis.

\section{DISCUSSION}

The classification of thyroid neoplasia relies predominantly on morphology; however, difficult cases that defy precise classification on morphologic grounds are not infrequently encountered. More recent, immunohistochemistry has been recognized as an adjunct to the classification of thyroid neoplasia. The most striking example is the use of calcitonin and neuroendocrine marker immuno- 


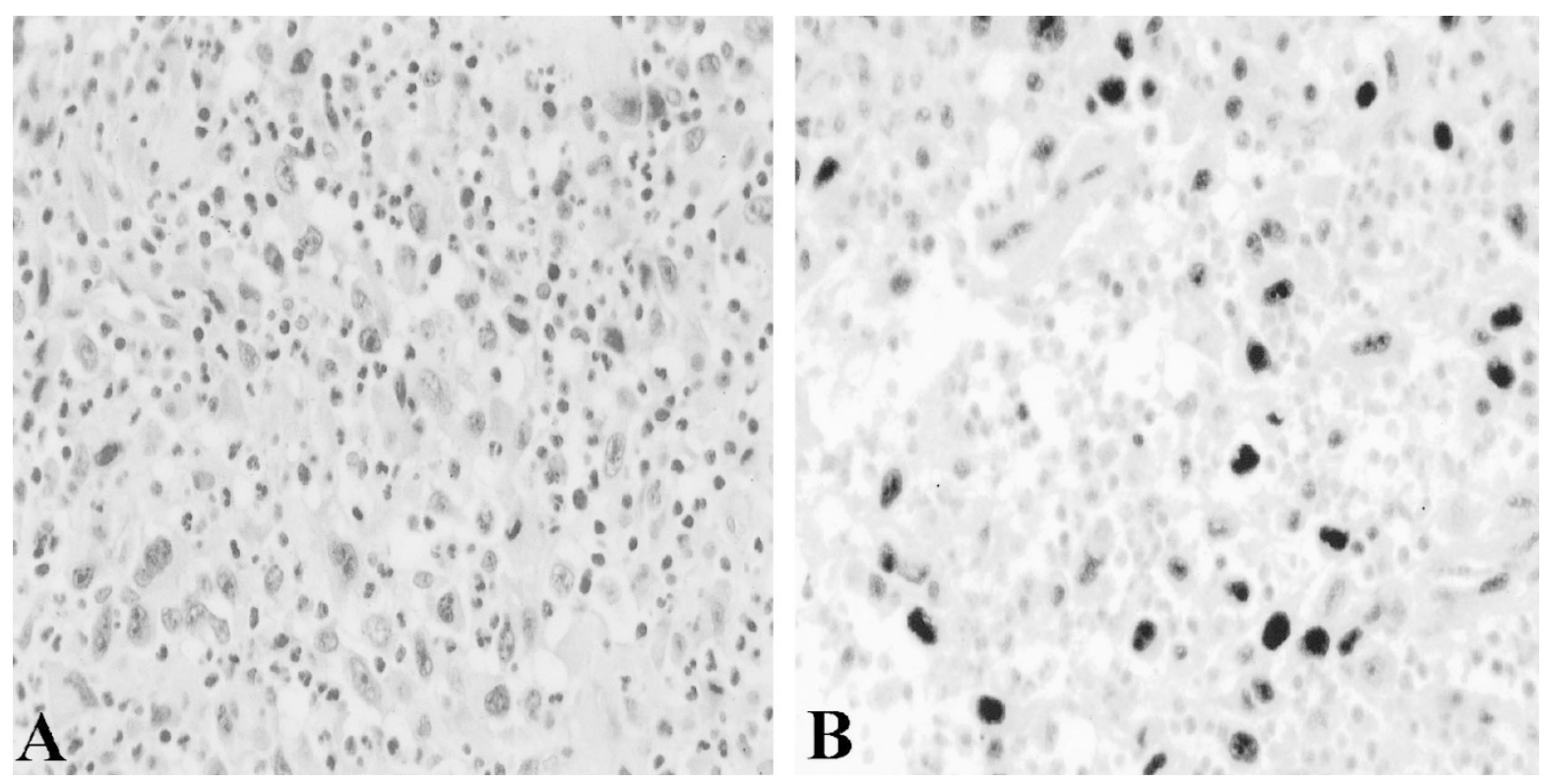

FIGURE 2. A, anaplastic thyroid carcinoma (hematoxylin and eosin). B, same anaplastic carcinoma showing retinoblastoma immunoreactivity in most nuclei. Note that prominent infiltrating lymphocytes are also occasionally positive (retinoblastoma immunohistochemistry with diaminobenzidine chromogen and nickel chloride enhancement to produce a black positive signal).

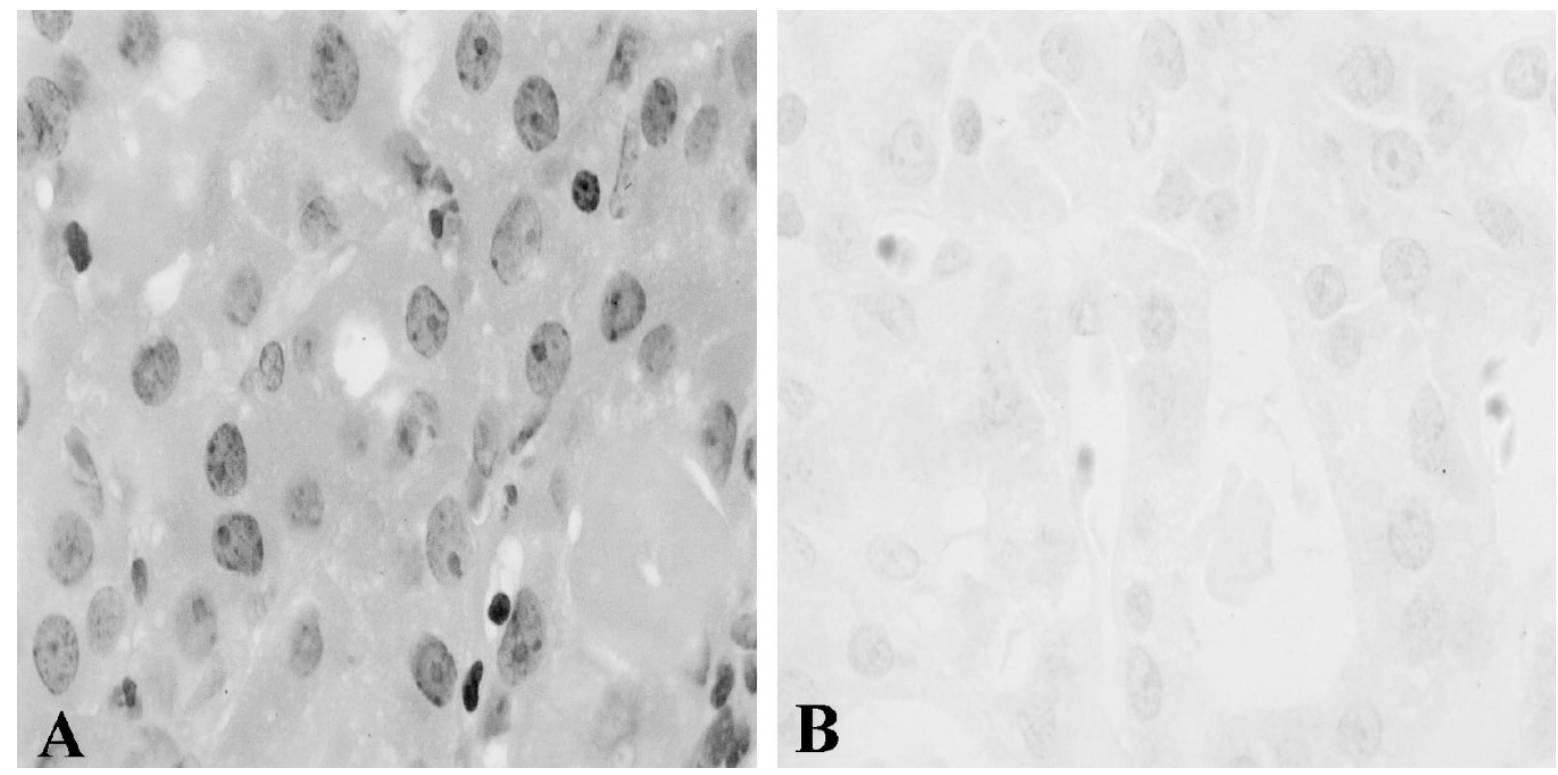

FIGURE 3. A, Hürthle cell adenoma showing characteristic granular eosinophilic cytoplasm and prominent nucleoli (hematoxylin and eosin). B, same Hürthle cell adenoma showing absence of retinoblastoma immunoreactivity (retinoblastoma immunohistochemistry with diaminobenzidine chromogen and nickel chloride enhancement to produce a black positive signal).

histochemistry to discriminate medullary carcinoma from thyroid neoplasms of follicular origin (38). Other antibodies have been investigated for their ability to discriminate benign and malignant thyroid pathology. Although a plethora of studies have been published recently, only a few antibodies have demonstrated reasonable accuracy in discriminating benign from malignant thyroid neoplasms. The reported potentially beneficial antibodies include HBME-1 $(39,40)$, galectin-1 and galectin-3 (41), and now Rb-1 on the basis of this report.

In the present study, we detected Rb-1 antibody reactivity in the majority of the benign non-Hürthle thyroid lesions (51 of 53 [96\%]), whether hyperplastic nodular goiters or presumably neoplastic solitary follicular adenomas. The one notable exception to this pattern in benign lesions was observed in Hürthle cell neoplasms, which lacked Rb-1 immunoreactivity in both benign and malignant lesions. Malignant thyroid neoplasms in general and conversely lacked reactivity with the antibody in the majority (42 of 51 [82\%]). These overall results indicate the potential utility of the Rb-1 antibody in conjunction with morphology in the distinction between benign and malignant thyroid neoplasms in general surgical pathology practice. 
The most promising application of $\mathrm{Rb}$ immunohistochemistry, based on our results, relates to the distinction of the follicular variant of papillary carcinoma or minimally invasive follicular carcinoma on one hand from follicular adenoma on the other. Not infrequently, these particular differential diagnoses can be problematic. The difficulties concern the potential focality of the nuclear changes in papillary carcinoma and that the typical scarring or infiltrative growth patterns of the follicular variant of the papillary carcinoma may be inconspicuous. Similarly, discriminating true capsular and vascular invasion of minimally invasive follicular carcinoma from benign epithelial herniation into or trapping of benign tissue within the capsule of an adenoma can also be challenging. Rb-1 nuclear immunoreactivity in such lesions would provide adjunctive data in favor of a follicular adenoma, whereas absence of staining would favor malignant alternatives, in conjunction with the morphologic findings. Based on our results, a negative $\mathrm{Rb}$ immunostain had a sensitivity of $89 \%$ for differentiating follicular carcinoma from adenoma $(95 \% \mathrm{CI}=[52 \%, 99.7 \%])$, whereas the specificity for a positive $\mathrm{Rb}$ immunostain in this differential diagnosis was $100 \%(95 \%$ $\mathrm{CI}=[85 \%, 99.9 \%])$. Similarly, the estimated sensitivity and specificity for differentiating a papillary carcinoma (follicular variant) from follicular adenoma on the basis of a negative $\mathrm{Rb}$ immunostain are $100 \%(95 \% \mathrm{CI}=[69 \%, 100 \%])$.

Another potentially useful application of $\mathrm{Rb}$ immunohistochemistry is the distinction between changes after fine-needle aspiration of follicular adenomas in the form of scarring, hemorrhage, and vertical capsular pseudoinvasion, as described previously (42), from true invasion in follicular carcinoma. In the last case, lack of Rb immunoreactivity would favor the diagnosis of carcinoma, whereas a high percentage of positive cells, along with a history of fine-needle aspiration biopsy, would support a benign process.

Reactivity of Rb-1 with follicular adenomas and nodular goiter was detected in the majority of the cells in all cases that we studied. None of 34 cases of follicular adenoma and 2 of 19 cases of nodular goiter lacked $\mathrm{Rb}$ expression, all with internal positive control staining of adjacent thyroid epithelial and mesenchymal cells. These findings suggest that the loss of protein expression can be seen in benign lesions. An alternative may be that these lesions were in the process of malignant evolution.

The intensity of staining for P-Rb within some thyroid lesions varied from cell to cell in our study, also similar to previous reports $(29,33,43)$. Despite this variability, the distinction between positive and negative cases was always easy to assess at the $10 \%$ cutoff level that we used.
The series of Hürthle cell neoplasms examined herein lacked expression of $\mathrm{Rb}-1$ in both benign and malignant lesions, except for a single Hürthle cell carcinoma that reacted with the antibody in $\sim 50 \%$ of the cells' nuclei. This staining pattern for Rb-1 in Hürthle neoplasms suggests that mechanisms other than $\mathrm{Rb}$ alteration are involved in this category of thyroid neoplasia, similar to many other biologic and molecular aspects that distinguish this subset of thyroid neoplasms (44). This same pattern of absence of Rb-1 staining was observed in Hürthle cell metaplasia in a case of Hashimoto's thyroiditis that we also stained (data not shown). This case also harbored an Rb-positive follicular nodule, in contrast to the negative metaplastic Hürthle cells in the adjacent thyroid tissue.

All cases of insular and papillary carcinoma were negative for Rb-1, including both the classic type of papillary carcinoma and the follicular variant of papillary carcinoma. As for follicular carcinomas, eight of nine cases lacked expression of $\mathrm{Rb}$. In our series, only three of six cases of medullary carcinoma (50\%) showed loss of expression of $\mathrm{Rb}$, suggesting varied biologic mechanisms of tumorigenesis in these neoplasms. All four cases of anaplastic carcinoma included in this study reacted strongly and positively with $\mathrm{Rb}-1$ antibody, again suggesting either that other mechanisms operate in the transformation to anaplastic carcinoma or that the mutant $\mathrm{Rb}$ protein is immunoreactive as has been documented by Geradts et al. (32).

The study by Holm and Nesland (31) reported the presence of $\mathrm{Rb}$ protein product in the majority of their thyroid carcinomas in paraffin sections. This discrepancy in comparison to our results may be ascribed to four potential factors. First, the definition of positive results in Holm's study was based on any degree of reactivity with $\mathrm{Rb}$ antibody, whereas in our study, positivity is defined by Rb-1 staining in $10 \%$ or more of the epithelial lesional cells. Figge and colleagues (29) also used a $10 \%$ cutoff, based on positive nuclear surface area quantitated by image analysis. Assessing a neoplasm as positive for $\mathrm{Rb}$ protein expression when in fact only a small minority of the cells are reacting discounts that normal non-neoplastic tissue may express $\mathrm{Rb}$ protein at any given time. There may be contamination of neoplasms by a minority of nonneoplastic epithelial cells, or a minority of positive neoplastic cells may reflect tumor heterogeneity or oligoclonality. Thus, accepting any reactivity does not seem to be the best approach for distinguishing benign from malignant neoplasms. This is particularly true given that in the setting of neoplasia, a significantly larger number of cells may be in late G1-M phase (45) as compared with normal tissue, and in these phases of cell cycle, the total level of $\mathrm{P}-\mathrm{Rb}$ is higher compared with G0/mid G1, as shown 
by Xu et al. (43). The best arbitrary cutoff between benign and malignant would be a percentage taking into account the background level of positivity in cycling cells. In our study and in the study by Figge et al. (29), a $10 \%$ cutoff proved to have excellent discriminatory power. In addition, when the tissues were positive, they were consistently significantly higher than the $10 \%$ cutoff. In fact, 48 of 51 positive benign lesions (94\%) were positive in more than $50 \%$ of nuclei, making the distinction between positive and negative cases easily achievable. Second, Holm et al. used a different Rb antibody clone that may bind to different epitopes in the target $\mathrm{Rb}$ antigen that might be associated with nonspecific binding to other nuclear antigens. Differences between $\mathrm{Rb}$ clones have been documented previously by Geradts et al. (33) and confirm our personal observations in our referral service. Third, interlaboratory differences in the handling of tissues and quality control procedures might be responsible for the differences in the results. Fourth, endogenous biotin activity in the thyroid tissue has been documented by Kashima et al. (34). This factor makes evaluating nuclear positivity in the midst of dark false-positive cytoplasmic background challenging and increases the likelihood of false positives. We observed this same artifact when we tried using the microwave only method of antigen retrieval; this yielded a high cytoplasmic background that prohibited accurate estimation of the number of positive nuclei in any single section. Subsequent pronase digestion eliminates this problem.

Although the gold standard for classifying follicular cell-derived thyroid lesions as benign or malignant is based on morphology, the future may continue to add adjunctive techniques, such as immunohistochemistry, into the diagnostic triage. $\mathrm{Rb}$ immunohistochemistry is a promising candidate.

\section{REFERENCES}

1. Knudson AG Jr. The genetics of childhood cancer. Cancer 1975;35(Suppl 3):1022-6.

2. Knudson AG Jr, Hethcote HW, Brown BW. Mutation and childhood cancer: a probabilistic model for the incidence of retinoblastoma. Proc Natl Acad Sci 1975;72(12):5116-20.

3. Knudson AG Jr, Meadows AT, Nichols WW, Hill R. Chromosomal deletion and retinoblastoma. N Engl J Med 1976; 295(2):1120-3.

4. Lee W-H, Shew J-Y, Hong FD, Sery TW, Donoso LA, Young LJ, et al. The retinoblastoma susceptibility gene encodes a nuclear phosphoprotein associated with DNA binding activity. Nature 1987;329:642-6.

5. Lai A, Marcellus RC, Corbeil HB, Bronton PE. RBP1 induces growth arrest by expression of E2F-dependent transcription. Oncogene 1999;18(12):2091-100.

6. Brown VD, Philips RA, Gallie BL. Cumulative effect of phosphorylation of pRB on regulation of E2F activity. Mol Cell Biol 1999;19(5):3246-56.

7. Helin K, Harlow E, Fattaey A. Inhibition of E2F-1 transacti- vation by direct binding of the retinoblastoma protein. Mol Cell Biol 1993;13(10):6501-8.

8. Rubin E, Tamrakar S, Ludlow JW. Protein phosphatase type 1 , the product of retinoblastoma susceptibility gene, and cell cycle control. Front Biosci 1998;3:D1209-19.

9. Yamasaki L, Bronson R, Williams BO, Dyson NJ, Harlow E, Jacks T. Loss of E2F1 reduces tumorigenesis and extends the life span of $\mathrm{Rb}( \pm)$ mice. Nat Genet 1998;18(4):360.

10. Shew JY, Ling N, Yang XM, Fodstadt O, Lee WH. Antibodies detecting abnormalities of the retinoblastoma susceptibility gene product (PP $1109(\mathrm{Rb})$ ) in osteosarcomas and synovial sarcomas. Oncogene Res 1989;4:205-14.

11. Cance WG, Brennan MF, Dudas ME, Huang C-M, CordonCardo C. Altered expression of the retinoblastoma gene product in human sarcomas. N Engl J Med 1990;323:145762.

12. Ichimura K, Schmidt EE, Goike HM, Collins VP. Human glioblastomas with no alterations of the CDKN2A (P16 INK4A, MTS1) and CDK4 genes have frequent mutations of the retinoblastoma gene. Oncogene 1996;13(5):1065-72.

13. Huang H-JS, Yee J-K, Shew J-Y, Chen P-L, Bookstein R, Friedmann T, et al. Suppression of the neoplastic phenotype by replacement of the $\mathrm{Rb}$ gene in human cancer cells. Science 1988;242:1563-6.

14. Bookstein R, Rio P, Madreperla SA, Hong F, Allred C, Grizzle WE, et al. Promoter deletion and loss of retinoblastoma gene expression in human prostate carcinoma. Proc Natl Acad Sci U S A 1990;87:7762-6.

15. Bookstein R, Shew J-Y, Chen P-L, Scully P, Lee W-H. Suppression of tumorigenicity of human prostatic carcinoma cells by replacing a mutated RB gene. Science 1990;247: 712-5.

16. Varley JM, Armour J, Swallow JE, Jeffreys AJ, Ponder BAJ, Tang A, et al. The retinoblastoma gene is frequently altered leading to loss of expression in primary breast tumors. Oncogene 1989;4:725-9.

17. Xu HJ, Hu SX, Cagle PT, Moore GE, Benedict WF. Absence of retinoblastoma protein expression in primary non-small cell lung carcinomas. Cancer Res 1991;51:2735-9.

18. Cagle PT, El-Naggar AK, Xu HJ, Hu SX, Benedict WF. Differential retinoblastoma protein expression in neuroendocrine tumors of the lung. Potential diagnostic implications. Am J Pathol 1997;150(92):393-400.

19. Benedict WF, Lerner SP, Zhou J, Shen X, Tokunaga H, Czerniak B. Level of retinoblastoma protein expression correlates with P16 (MTS-1/INK4A/CDKN2) status in bladder cancer. Oncogene 1999;18(5):1197-203.

20. Horowitz JM, Park S-H, Bogenmann E, Cheng JC, Yandell DW, Kaye FJ, et al. Frequent inactivation of the retinoblastoma anti-oncogene is restricted to a subset of human tumor cells. Proc Natl Acad Sci 1990;87:2775-9.

21. Frauman AG, Moses AC. Oncogenes and growth factors in thyroid carcinogenesis. Endocrinol Metab Clin North Am 1990;19:479-93.

22. Aasland R, Lillehaug JR, Male R, Josendal O, Arhaug JE, Kleppe K. Expression of oncogenes in thyroid tumors: coexpression of C-erbB2/neu and C-erb B. Br J Cancer 1988; 57:358-63.

23. Wyllie FS, Lemoine NR, Williams ED, Wynford-Thomas D. Structure and expression of nuclear oncogenes in multistage thyroid tumorigenesis. Br J Cancer 1989;60:561-5.

24. Namba H, Rubin SA, Fagin J. Point mutations of ras oncogenes are an early event in thyroid tumorigenesis. Mol Endocrinol 1990;4:1474-9.

25. Lemoine NR, Mayal ES, Wyllie FS, Williams ED, Goyns M, Stringer B, et al. High frequency of oncogene activation in all stages of human thyroid tumorigenesis. Oncogene 1989;4: 159-64. 
26. Harvey M, Vogel H, Lee EY, Bradley A, Donehower LA. Mice deficient in both P53 and Rb develop tumors primarily of endocrine origin. Cancer Res 1995;55(5):1146-51.

27. Holm R, Nesland JM. Retinoblastoma and P53 tumor suppressor gene protein expression in carcinomas of the thyroid gland. J Pathol 1994;172(3):267-72.

28. Soares P, Cameselle-Teijeiro J, Sobrinho-Simoes M. Immunohistochemical detection of P53 in differentiated, poorly differentiated and undifferentiated carcinomas of the thyroid. Histopathology 1994;24(3):205-10.

29. Figge J, Bakst G, Weisheit D, Solis O, Ross JS. Image analysis quantitation of immunoreactive retinoblastoma protein in human thyroid neoplasms with a streptavidin-biotin peroxidase staining technique. Am J Pathol 1991;139(6):1213-9.

30. Zou M, Shi Y, Farid NR, Al-Sedairy ST. Inverse association between cyclin D1 overexpression and retinoblastoma gene mutation in thyroid carcinomas. Endocrine 1998;8(1):61-4.

31. Holm R, Nesland JM. Retinoblastoma and P53 tumor suppressor gene protein expression in carcinomas of the thyroid gland. J Pathol 1994;172(3):267-72.

32. Geradts J, Kratzke RA, Crush-Atanton S, Shu Fen Wen, Lincoln CE. Wild type and mutant retinoblastoma protein in paraffin sections. Mod Pathol 1996;9:339-47.

33. Geradts J, Hu S-X, Lincoln CE, Benedict WF, Xu H-J. Aberrant $\mathrm{Rb}$ gene expression in routinely processed, archival tumor tissues determined by three different anti-Rb antibodies. Int J Cancer 1994;58:161-7.

34. Kashima K, Yokoyama S, Daa T, Nakayama I, Nickerson PA, Noguchi S. Cytoplasmic biotin like activity interferes with immunohistochemical analysis of thyroid lesions: a comparison of antigen retrieval methods. Mod Pathol 1997;10:515-9.
35. LiVolsi VA, Merino MJ. Histopathologic differential diagnosis of the thyroid. Pathol Annu 1981;16(Pt 2):357-406.

36. LiVolsi VA. Surgical pathology of the thyroid. In: Zorab R, Bennington JL, editors. Major problems in pathology. Vol. 22. 1st ed. Philadelphia: W.B. Saunders; 1990. p. 131-323.

37. Agresti, A. Categorical data analysis. New York: John Wiley \& Sons; 1990, p. 48-49, 249-250.

38. Gabriel, KR. Simultaneous test procedures for multiple comparisons on categorical data. J Am Stat Assoc 1966;61:108196.

39. Miettinen M, Karkkainen P. Differential HBME-1 reactivity in benign versus malignant thyroid tissue is helpful in the diagnosis of thyroid tumors [abstract]. Mod Pathol 1995;9: 50A.

40. Miettinen M, Karkkainen P. Differential reactivity of HBME- 1 and CD15 antibodies in benign and malignant thyroid tumors: preferential reactivity with malignant tumors. Virchows Arch Int J Pathol 1996;429:213-9.

41. Xu XC, El-Naggar AK, Lotan R. Differential expression of galectin-1 and galectin-3 in thyroid tumors. Potential diagnostic implications. Am J Pathol 1995;147(3):815-22.

42. LiVolsi VA, Merino MJ. Worrisome histologic alterations following fine-needle aspiration of the thyroid (WHAFFT). Pathol Ann 1994;29(Pt 2):99-120.

43. Xu H-J, Hu S-X, Benedict WF. Lack of nuclear Rb protein staining in G0/middle G1 cells: correlation to changes in total Rb protein level. Oncogene 1991;6:1139-46.

44. Bronner MP. Hürthle cell lesions of the thyroid. Pathol Case Rev 1997;2:200-9.

45. Harlow SP, Duda RB, Bauer KD. Diagnostic utility of DNA content flow cytometry in follicular neoplasms of the thyroid. J Surg Oncol 1992;50(1):1-6. 